\title{
Four Swiss Villages, 1860-1930: Putting Gender back into Historical Demography
}

\section{Anne-Françoise Praz}

Gender has become a central concept in the social sciences as a marker of the social and cultural elaboration of sexual difference and of power relations. In some disciplines however, its relevance has been more difficult to establish; this is notably the case for historical demography, as research has only recently made use of the connection between gender and demographic processes. ${ }^{1}$ This is rather astonishing, since the discipline deals with a range of questions where gender is basic, such as life courses of men and women, family and extended family relations, sexuality, childrearing and contraception.

The main purpose of this article is to show that the concept of gender is fundamental for historical demography and that it allows us to improve the explanatory power of the models used in this discipline. To begin with, I will identify some theoretical and methodological reasons that explain the late integration of gender in historical demography, and then focus on some current developments in the discipline that would help to overcome these blockages. This will be followed by two examples of the integration of a gender perspective in a central topic of historical demography, the so-called first demographic transition in Europe. Historians and demographers established that the secular decline of fertility in Europe occurred in two phases. A first decline in marital fertility took place in the late nineteenth and early twentieth centuries (1870-1930), and was realised through rudimentary birth control practices such as abstinence or withdrawal. There was a historically unprecedented shift from high numbers of children per family to fewer, but better nurtured and educated children. The elucidation of such a great social transformation has generated abundant research. ${ }^{2}$ The second fertility transition was initiated in the mid-1960s, thanks to the emergence and generalisation of modern contraceptive methods that could be controlled by women.

\section{Women's history and historical demography: mutual ignorance}

Women's history emerged as a discipline in the 1970s at the same time that historical demography was gaining importance, thanks particularly to the development of standardised and quantitative research procedures. Although its sources and methods could have provided part of the 'mass of information' that Virginia Woolf called for to fill in the gaps in the history of women - 'at what age did she marry; how many children had 
she as a rule; what was her house like? ${ }^{3}$ - historical demography and the emerging women's history did not, in fact, meet. It is not the aim of this paper to explore the political or institutional reasons for this mutual ignorance. ${ }^{4}$ Instead, I shall examine some internal, methodological points, which could throw light on this lack of initial recognition and cooperation in order to speed up the integration of gender in historical demography. Most of the scientific misunderstandings and divergences are rooted in two related problems: on the one hand in women's history, the experiences of individuals were not convincingly integrated into causal explanations of changing behaviours and the resulting social change; on the other hand in historical demography, individuals vanished into the aggregate.

The considerable achievements, but also the limits, of women's history are well known; ${ }^{5}$ here, I will underline some of the salient points. As Gisela Bock suggested, women's history, by making women a subject of research, rendered historically visible both women's subjection and their subjectivity. Concepts of 'male domination' and of 'consciousness' were central to this project.

The concept of 'male domination' tended to be used ahistorically and was of little help in understanding the mechanisms through which the unequal power relations between the sexes changed or reproduced through history. To document women's oppression, scholars resorted to the abundant normative discourses aimed to regulate women's behaviour, though often without examining their impact. As far as women's history was concerned, the chief institution of male domination and women's oppression, in the view of most feminists of that period, was the private sphere of the family. This conceptualisation led to a disregard of the family as a research topic, contrasting with its centrality in historical demography, and to a focus mainly on individual women beyond family ties, on their struggles in the public sphere of work, of social action and politics. ${ }^{6}$ Women's experiences in the family were neglected, even when they could have provided interesting insights for documenting the changing condition of women. For instance, the first fertility transition, by reducing the number of children per family, drastically modified the situation of the vast majority of mothers and the length of women's childbearing years dropped dramatically. ${ }^{7}$

The second concept, 'consciousness', highlighted the meanings women gave to their experiences, as well as women's individual or collective actions actively to shape their own lives. Through biographies and studies exploring women's culture or specific groups or movements, women's experiences and agency were brought into history. Scholars relied primarily on literary sources, above all personal testimonies in the form of letters, autobiographies and oral history, as more suitable to reveal women's subjectivities. Often the mechanisms through which this consciousness modified behaviours and led to social change remained elusive. Consequently, the connection between women's experiences with broader historical processes and structures was not clearly articulated. As a result, individual women were often conceptualised in contradictory ways, viewed either as independent actors or as victims of forces outside their control. $^{8}$

In contrast, historical demographers in the 1970s ignored perspectives of subjectivity and individual agency. There were two main reasons for this. Subjectivities and meanings are not dimensions that are easily measurable. They clashed with the very same methodological procedures, namely measurement and quantification, which 
gained scientific acceptance for historical demography as a discipline. Demographers were more interested in behaviour more easily quantifiable and actions that are regarded as the proximate determinants of social change. Consequently, individual events like marriage or childrearing were discussed as measurable occurrences within a population, with little reference to specific experiences of individuals. Women's history was very sceptical of quantification, which was seen as 'positivistic' and neglectful of important questions about women and family. This belief was strengthened by the fact that quantification often relied on historical statistical material that is fraught with gender bias.

Neither individual agency nor real individuals were in the picture. Historical demography addressed households and demographic rates, rather than women and men as actors or subjects. Even when data were collected at the individual level, the methods used tended to aggregate individual units like family members, or individual events like births, marriages and deaths, in order to obtain household structures or average demographic rates. Patterns of variation were explained either by strictly demographic mechanisms (for example, the number of births, marriages and deaths as the 'proximate determinants' of the composition of kin groups), or by large-scale impersonal, structural forces like increasing urbanisation and industrialisation. Such explanations did not try to relate these structural features to individual characteristics, but merely established correlations between macro-variables: for example, declining fertility in a given region was explained by the decreasing proportion of its population employed in agriculture, instead of showing how certain types of agricultural production determined the living conditions and the costs and benefits of children. ${ }^{9}$ From data collection to the final explanation, the 'individual' progressively vanished, first as a unit of analysis, and then as a conscious and possibly active agent in the process under study. The consequences of a given demographic rate or a given household structure in the everyday life of men and women were neglected and differences in their life courses were not seen as appropriate subjects of research, although the relevant data were often available. As Alison Mackinnon correctly observed of the debate on the fertility transition, demographers had portrayed fertility as 'a characteristic of populations rather than of persons'. ${ }^{10}$

Historical demography was no less problematic and closely linked to the issue of individuals or aggregates when it came to power relations between the sexes. To be sure, historical demographers became aware of the inadequacy of explanations based on correlations between aggregates and they had begun to consider the individual as the unit of analysis, trying to identify mechanisms that could account for the influence of macro-structures on 'private' demographic behaviour. But, even when they claimed to comply with a methodologically individualist approach, many scholars failed to make the last and crucial step, namely the disaggregation of the family. In many standard demographic models, the 'household/family', the 'couple' or the 'parents' were taken as a unified subject, presupposing harmonious needs and aligned interests between women and men. Moreover, 'household' was often substituted for 'family', thus conflating kinship and contract relations (servants, lodgers, etc.) and the nuclear and extended family.

Feminist scholars in the fields of historical demography and anthropology, as well as in demography and economics reacted to these shortcomings. Ellen C. DuBois and her co-authors rightly criticised the historical approach that identified women with the 
family or the couple 'in a way that totally ignored their independent existence and hid the conflicts they had in and with the family institution'. ${ }^{11}$ The anthropologist Paola Tabet castigates demographers for their use of the concept of 'natural fertility', implying that human reproductive behaviour is 'natural' in the absence of fertility control. Such an approach reinforced the tendency to reduce women to their biological function of giving birth, ignoring the social dimension of human reproduction that is shaped by cultural norms and power relations. According to Tabet, this view overlooks the social rules of marriage and sexuality, whose purpose in traditional societies was often to institute power relations that assured a maximal exposure of women to the risk of childbearing. ${ }^{12}$ Susan Cotts Watkins, reviewing thirty years of the journal Demography, demonstrated that articles on fertility, marriage and the family were often built on unquestioned assumptions about women's behaviour (seen primarily as producers of children and of child services) and that issues of power within the family are ignored almost completely. ${ }^{13}$ The economic historian Nancy Folbre pointed out that any explicit consideration of economic inequalities between the sexes and between the generations was missing from explanations of fertility decline. She argued convincingly for the need to disaggregate the family unit, as the family is not 'a decision-making black box ... it is a group of individuals who make collective, but not necessarily consensual decisions' ${ }^{14}$ Alison Mackinnon resumed the criticisms made by feminist scholars of the analysis of the first fertility transition by historical demographers and pointed out new studies that attempt to integrate women's agency, the changing position of women and changing conjugal relations into the models.

\section{Gender and historical demography: the new meeting ground}

In the mid-1980s, women's history and historical demography introduced the concept of gender. This initiated decisive turns, enabling them to overcome previous problems and become susceptible to new and more open perspectives. The insights gained through developments in the history of gender relations have resulted in the current debate. How could historical demography integrate gender and enhance its explanatory models in making this concept workable for its specific field, and how, in turn, could historical demography improve the concept of gender itself? This article will investigate four new research directions for historical demography that arise from the introduction of gender: first, the impact of the gender system on the individual life courses of men and women; second, the importance of the gender system for family economy and demographic behaviour; third, the influence of gender norms on demographic processes like fertility and marriage; and finally, the way that institutions (especially the state), which are leading forces in the social construction of gender, influence demographic behaviour. In the following, we will sketch some attempts that have been undertaken to tackle these issues and discuss some remaining or emerging problems.

Historical demography is now better able to capture the individual characteristics of men's and women's lives. On the technical level, a more individual oriented approach is easier to realise with the method of life-course or event-history analysis. More individual destinies become accessible because the method overcomes the limitation of sources that previously restricted the study to those individuals pertaining to stable (non migrant) and conventional families, a bias which has often been criticised. Eventhistory analysis focuses on 'transitions in individual lives and the choices associated 
with them', for example the decisions to work, to leave the parental household, to marry, to bear children and so on. These individual events are used to construct a database, allowing the application of statistical models that show the interplay between the occurrence and the timing of each event on the one hand and, on the other hand, some family characteristics (siblings, death of one parent and so on), and specific individual attributes, both biological ones such as age, and social attributes such as civil status, occupation, religion, or geographical origin. The individual rather than the aggregate becomes the unit of analysis. For example, the question is no longer what proportion of households are headed by a single parent, but rather, under what conditions and what proportion of their lives children spend living with one parent. The tension between individual choice and family constraints is also addressed, as the models seize on the impact of changing historical conditions - for example, the availability of waged work and its impact on the extent that individuals could escape from familial obligations. George Alter's study of women's destinies in a Belgian town is a pioneering example. He brings into focus the everyday lives of ordinary women, showing how they struggle for their own and their relatives' well-being, how they move in and out of family households and how they shift from one status to another. ${ }^{15}$

This kind of analysis provides significant results, highlighting the differences and similarities between the individual lives of men and women from different classes and cultural settings, and testing the respective impact of family obligations and economic opportunities. However, some aspects often remain elusive in these studies: the link between these life-courses and the power relations between the sexes, as well as the link between these life-courses and the political processes and the cultural norms that shape gender status. Working patterns, for example, are related to the structural features of the economic environment, but not always to the legal framework, and the reasons behind the gender division between paid and unpaid work are not explored.

The importance of gender and age status, and of the power relations involved, has led to a more sensitive analysis of the family in the household economics approach. Its basic principles are inspired by the models of institutional economics that show how property rights, contractual obligations and social norms shape the distribution of resources, the bargaining power and the decision-making processes in such diverse organisations as families or firms. ${ }^{16}$ Instead of considering the family as a unified subject, this approach takes into account conflicts and compromises between its members, who are endowed with unequal resources and power. As the feminist economist Nancy Folbre has pointed out, these inequalities are not simply determined by market position, but largely by legal and cultural frameworks: the position of an individual in the family is related to the position of his/her social category, for example his/her sex category, in a given time and place. ${ }^{17}$ In her research on a peasant region of Spain (the Montes de Pas), Carmen Sarasúa identifies these intra-family inequalities, assessing each individual's participation in family work and each individual's access to family resources. The result is a hierarchical family organisation that redistributes family resources from female to male children, especially to assure the latter's education and career. This asymmetrical investment in male and female education was justified by social norms that defined the proper role of women (to serve God, care for the home and obey their husband), for which education was considered unnecessary. ${ }^{18}$ My own research, presented below, explores this particular discrimination in different religious and political contexts and tries to determine its impact on fertility differentials. 
Despite these developments, even recent research does not always consider the importance of both the thoroughgoing disaggregation of the family or take into account the bargaining power between the sexes. Alter's modelling of fertility decisions is a good example, as he still postulated the couple as the decision-maker in a paper published in 1992: 'couples must weigh the costs and benefits of life with one more child against the costs and benefits of life without another child plus the costs of preventing the birth of the next child'. ${ }^{19}$ This conflation leads historical demographers to misleading statements when they attempt to reintroduce individuals into the picture. Ronny Lesthaeghe, a prominent European demographer, provides a good example in his interpretation of the fertility transition debate, alleging that individual control of reproduction emerged during the 'first fertility transition'. This 'individual' turns out to be the couple; the author assumes that fertility decisions are a common interest or even consensual. Such a shortcut prevents scholars from investigating the power relations between spouses, as well as the historical change in gender norms and constraints. Actually, it is becoming clear that during the first fertility transition (1870-1930), gender norms usually forbade women to make any decision or even have knowledge of sexual matters; it was only during the second fertility transition (1965-onwards) that every individual concerned obtained the publicly accepted rights and the technical means to control their fertility. In overlooking this gender dimension, Lesthaeghe proposes a spurious delineation of the two fertility transitions, suggesting that 'the first fertility transition fully demonstrates the growing importance of individual autonomy that is individual freedom and refusal of an external moral authority'; this rebellion against moral authority was supposed to occur 'silently in the intimacy of the private sphere', contrasting with the second transition, when it broke out into the public sphere. ${ }^{20}$ Instead of this story of private versus public rebellion, it is rather the changing rights and resources of women that distinguish the second fertility transition from the first one.

As representations of sex differences, as well as informal norms of masculinity and femininity, are intimately connected with the changing meaning of sexuality and reproduction, they certainly influence demographic trends of nuptiality and fertility. Historical demographers are beginning to take this cultural aspect into account and have turned to the findings and methods of anthropology and cultural history, as well as to new sources (texts, or oral or written testimonies of individuals) and qualitative methods (for example, discourse analysis or interviews). ${ }^{21}$ Kate Fischer's oral history study of the fertility decline among the British working class provides an interesting example. She challenges the previous, but untested, assertion that women were the leading force in the adoption of birth control during the first fertility transition because of their greater interest in the matter. Actually, given the contraceptive means then available and given the dominant gender culture in the British working-class families she studied, respectable wives were expected to be ignorant about sexual matters while husbands were able to decide unilaterally about contraception and generally did. ${ }^{22}$ Such a result has to be tested in other population groups and the question to what extent women had influence or autonomy in birth control issues remains a matter of debate. The use of abortion as a contraceptive technique controlled by women has been suggested by many scholars, ${ }^{23}$ and the rate of abortion among marrying women rising considerably around 1900 in many European countries - could indicate their determination to terminate pregnancies. However, it remains questionable whether abortion was a display of women's power to control their fertility in a self-determined 
manner or a last resort when male-dominated practices such as withdrawal had failed.

The concept of gender has thus increasingly enriched the study of the cultural components of fertility behaviour, hitherto limited to the impact of religious and linguistic factors. However, these new approaches should not reintroduce the misleading opposition between cultural and economic causes of demographic behaviour, particularly fertility, which historical demographers have striven to overcome. For this reason, they have relied on economic decision models that offer a general explanation of individual decisions and permit the transformation of all types of contextual features, material and cultural, into the same kind of 'theoretical money', costs and benefits. Fertility behaviour can thus be considered as responding to various cost-benefit incentives: the material cost of children, the information cost of contraception, the moral cost of contraception depending on religious doctrine, the social cost of having more or fewer children according to the ideal of parenthood in a specific class, or the social cost of a given sexual behaviour according to gender norms.

A gender perspective points to the fact that wives and husbands are positioned differently with respect to each kind of cost. This perspective is certainly more fruitful than a model that tries to assess the pre-eminence of cultural factors over material ones or vice versa. For example, John Gillis contrasts the 'economistic' argument of changing costs of children during the first fertility transition with the cultural argument of the changing meaning of fatherhood and motherhood, which he considered more significant. $^{24}$ Notwithstanding the importance of changing meanings of parenthood, I would argue that this change provokes in turn a change in the costs of children, to whom more time and goods are dedicated. Moreover, it is only by observing and measuring an effective change in the costs of children in some social group, that historical demographers are able to demonstrate the mechanism through which a change in the meaning of parenthood actually induces a change in fertility behaviour. Undoubtedly, linking qualitative insights about the meanings individuals give to their experiences to demographic results remains a great challenge for demographers. Nevertheless, by elucidating and testing such links, explanatory models of demographic behaviour become more convincing.

A fourth direction of research provides insights into the crucial mechanisms that transform norms into effective costs for individuals, shaping the decisions they have to face, especially in regard to fertility control. Such studies, called the 'political economy of fertility' ${ }^{25}$ emphasise the role of state policies in regulating fertility behaviour. This is especially true for the second part of the nineteenth century onwards, when state institutions gained importance in regulating family life, compared to religious or other traditional institutions. As S. Ryan Johansson proposed, it was not through public policies overtly planned to influence demographic trends that the state was really efficient, for pro-natalist policies generally failed, but through 'implicit policies' that modified the rights and responsibilities of certain categories of individuals and, consequently, influenced the cost-benefit balance determining demographic behaviour. ${ }^{26}$ Fertility trends were largely related to school policies that gave more rights to children and thereby increased the costs of their upbringing. There is also a strong relationship between the opportunity costs of childrearing and the gendered structure of the labour market, namely the extent of discrimination against women. State policies such as work 
legislation and social measures influenced the distribution of gender roles in the labour market and thus modified these costs. ${ }^{27}$

When historical demographers highlight the central role of institutions in the mechanisms translating norms and laws into effective costs influencing fertility decisions, they must take gender into consideration. Since institutional processes attribute rights and responsibilities to individuals according to categories, it is impossible to avoid the fact that categorisation by sex is historically one of the most pervasive. Notably, during the first fertility transition, gender was a prominent target of state policies. Norms of femininity and masculinity prescribed different behaviours regarding sexuality and contraception; women and men were not subject to the same work legislation, girls and boys were not considered equal in curricula and in public expenditure on education. However, the process is not unidirectional, as historical conditions also give individuals opportunities to challenge the social norms and modify the institutional processes in favour of gender equality. For example, the better education of women gives them more consciousness and facilitates the emergence of social movements fighting for women's emancipation. Yet, the integration of this gendering process in the explanatory models of historical demography still remains relatively undeveloped. In the following section, two examples of how this integration can be realised are presented.

\section{The first fertility transition in two Swiss regions}

The first fertility transition that occurred in Europe at the turn of the twentieth century is described as the shift in demographic structures away from high levels of celibacy, high rates of births and deaths and late ages of marriage, and towards low levels of births and deaths, as well as early and universal marriage. The marked decline in marital fertility between 1870 and 1930, through the generalisation of rudimentary birth control practices such as abstinence and withdrawal is particularly fascinating. In Switzerland, for example, the average number of children per woman of childbearing age dropped from 4.3 to 2.1 during this period. While the statistical dimensions of this phenomenon are nowadays well established, demographers still cannot satisfactorily explain the various paths and timings of this momentous change.

Switzerland figures as a miniature laboratory to study this decline, because of its cultural diversity especially in language and religion, as well as its political organisation. A long historical antagonism between Catholics and Protestants limited the contact between the different geographical areas and thus upheld heterogeneity. A strong federalism gave the governments of the twenty-three cantons important powers and autonomy in many domains. As a result, the impact of these various policies on fertility behaviour can easily be compared.

The first purpose of the study was to examine the impact of cultural factors like religion and political ideology on fertility. Therefore, two French-speaking cantons were selected that differed in these respects: the canton of Vaud, Protestant and led by progressive authorities, and the canton of Fribourg, Catholic with a conservative government. In order to isolate the impact of cultural variables, two villages were selected in each canton with respect to contemporaneous socio-economic factors. The first pair of villages simultaneously experienced the same industrialisation process (a chocolate factory). The second pair, two neighbouring communities, maintained an economic structure based on agriculture and fishing (Figure 1). A database of 


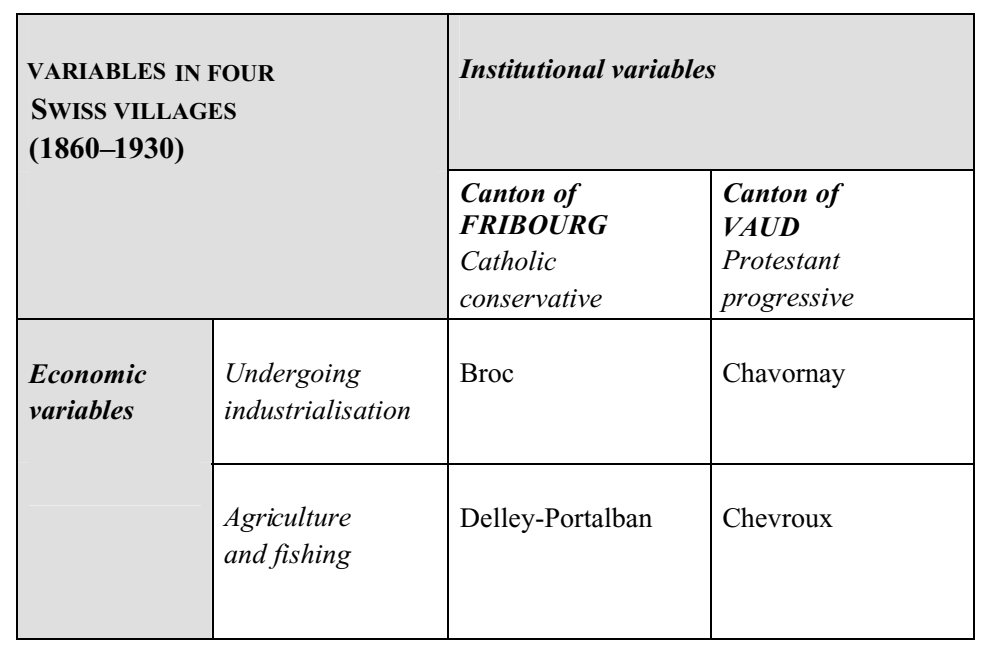

Figure 1: Demographic Variables in Four Swiss Villages (1860-1930)

information about fertility behaviour was created. The parochial and civil registers provide the basis for family reconstruction including marriages celebrated between 1860 and 1930 that produced 5,381 legitimate births for 1,848 married and fecund women under observation.

In spite of the very similar economic conditions, the fertility decline in the Catholic villages took place far later. The usual explanation given by historical demography for such a variation refers to the prohibition of contraceptive practices in Catholic doctrine. But such an explanation is problematic, because the implementation of this part of Catholic doctrine was not effective at this time. Indeed, around 1900, the Catholic Church preferred not to recall the faithful to the path of sexual morality, in order to avoid conflicts that might have initiated or accelerated the process of secularisation already underway. ${ }^{28}$ In Fribourg, the Catholic authorities expressed no clear warning against contraception before the late $1920 \mathrm{~s} .{ }^{29}$ It is therefore important to explore other components of religious and political culture that could account for such a difference in fertility behaviour: the gender system.

\section{Gender inequalities in education and fertility decline}

In a pioneering article, John Caldwell argued that 'the primary determinant of the timing of the onset of the fertility transition is the effect of mass education on the family economy' ${ }^{30}$ Since it increases the cost of children, education constitutes an important incentive to practise birth control, all the more so when compulsory schooling is rigorously implemented by the state. Several studies have analysed the influence of education on fertility using a gender approach, most of them examining the influence of the mother's education on their fertility level. ${ }^{31}$ A classic procedure is to use the mother's educational attainment as an explanatory variable. My study highlights another process, focusing on the costs of education for boys and girls and on the differential use of boys or girls in family work as economic incentives susceptible to postpone or 
to accelerate the adoption of birth control. What was the impact of school policies on fertility, taking into account the fact that these policies were gendered, and that this gender dimension varied according to political and religious culture?

I therefore attempted to document the investment in children's education by the parents in the villages studied. Administrative sources (pupil listings, school attendance statistics and correspondence from the school authorities) ${ }^{32}$ provided indications about the school career of the children, and were augmented by assumptions based on the subsequent professions of these children at marriage or death. For the 5,042 legitimate children who survived until age fifteen, we managed to reconstitute the school career of 2,353 of them (1,333 boys and 1,020 girls). ${ }^{33}$ For each canton, in order to detail attitudes towards education, we selected qualitative material such as political discourse, educational periodicals and school manuals, as well as the effective state policies as proclaimed in official publications, legislation and correspondence between cantonal and local authorities.

The importance of education in general and its relevance for women in particular was viewed very differently in the two cantons, as a content analysis of this material demonstrates. ${ }^{34}$ In the Protestant and progressive culture of Vaud, both men and women were supposed to develop the intellectual capacities God had given them, for their own spiritual enlightenment and for the improvement of civic virtues. ${ }^{35}$ In Protestant educational periodicals, knowledge was considered important for women, the mothers of future citizens. Even the fact that they had no political rights and that their future social role would keep them bound to the home were not judged reason enough for limiting their scope: girls had to study history and geography to learn 'the progress of the institutions and the advent of democracy', and to know 'where the rice and the coffee they use every day come from' ${ }^{36}$ The school reading books present the mother as playing an important role in children's schooling where she is often depicted checking their homework and exercise books. ${ }^{37}$ In the Catholic and conservative culture of Fribourg, knowledge was considered as potentially dangerous, a source of the sin of pride or of rebellion against the established authorities. According to Catholic educational periodicals, girls' education had to prepare skilled and pious housekeepers. The texts contrasted this ideal with two discredited feminine figures that absolutely were to be avoided: the coquettish woman and the learned woman. The rhetoric often joined these figures in the same sentence, inducing the idea that knowledge is a vanity, even a sin for women, and that too learned a woman would represent a danger for family and society. ${ }^{38}$ The girls' school programme, in accordance with their social destiny, was forced to make a large place for housekeeping and needlework, limiting the study of other disciplines to the most basic skills. In the school reading books, the exemplary mother never worries about school and homework, but teaches her child to pray and only recommends that he or she obey the teacher, who is God's representative.

These respective discourses and ideologies shaped school policies. The Protestant canton implemented compulsory schooling more efficiently, as school attendance was regularly controlled and absenteeism severely repressed. Parents could not take their children out of school to use them as workers before they reached the legal age of sixteen, whatever their sex, and exceptions were extremely rare. Coeducation was the rule until the age of sixteen, which limited gender differences in access to disciplines and programmes. Post-primary education for girls and boys was 
recommended and fostered by the decentralisation of secondary or professional schools, and girls' educational institutes for post-primary education received public support. In the Catholic canton, school policies were sharply gender-biased. The control and repression of school absenteeism was relatively haphazard, particularly for girls. School structures were mostly segregated by sex; the cantonal authorities provided post-primary public - and free - schools for boys only, leaving girls' post-primary education to religious and private educational institutes that only rich families could afford. Above all, the school system permitted many exceptions in school attendance for teenagers, especially for girls, whose parents often took them out of school before the legal age.

Using the event-history analysis method, the study finally examined the impact of these gendered ideologies and policies on the effective parental investment in children's education. The statistical models used make it possible to measure the factors influencing two aspects for each child's life course: first, the chance of attending a post-primary school which implied significant monetary costs for the parents including fees, books, travel and maintenance; second, the moment that each child left school for work, which indicates the opportunity costs that parents incurred, because the longer the child attended school, the later he or she contributed to the family budget. ${ }^{39}$ The difference between the two religious cultures in these areas is striking. Among the factors that modified a child's chance of attending post-primary school, the variable male sex multiplied this chance by only 2.45 in the Protestant canton, compared to 4.75 in the Catholic canton. When we observe the risk of leaving school earlier, this was particularly high for Catholic girls compared to Catholic boys, while the gender difference was very small in the Protestant sample.

These results demonstrate that Protestant parents met with substantial costs for the education of their children, both boys and girls, which, I would argue, constituted an important incentive to practise birth control. The most marked decline in fertility for both Protestant villages, whatever their economic structure, occurred simultaneously in the last twenty years of the nineteenth century, which is precisely when compulsory schooling was implemented in the canton. In the Catholic canton, although compulsory schooling was implemented at the same time, this did not initiate the fertility transition. The causal links seem to be straightforward: in permitting marked discrimination against girls, the school policies allowed Catholic parents to avoid considerable education costs and birth control was thus less imperative for Catholic families.

Institutional regulation was also shaped by the attitudes of the families towards school policies, sometimes generating acute conflict and local resistance. Careful analysis of such conflicts shows that compromises were mainly to the cost of girls' education. In the Catholic canton, the government granted many individual exceptions to parents opposed to mandatory schooling; as a rule, the parents concerned used this opportunity to take their girls out of school. Instead of opting for a similar individualised procedure, the Protestant canton of Vaud preferred to endow local authorities with more leeway. These were allowed to fix the girls' age of liberation from compulsory schooling one year earlier than for boys; this decision, taken every year by the local council, had a collective effect for all the girls in the commune. However, as the influence of lower-class family heads (who were more dependent on child labour) was weak in these councils, parents who saw it in their interests to increase the education of girls were able to impose their views.

This analysis shows how the integration of gender into the explanatory model 
throws new light on the delay of fertility decline for Catholic populations; this delay has been attested to in many demographic studies, yet a full understanding of the mechanisms of the influence of religion is still a matter of debate. Conversely, it is also important for gender history to take into account certain results of demographic research that provide empirical evidence, as in this example showing the differences in discrimination against girls according to religious culture. Research in gender history often investigates the change of gender norms in diverse discourses and their implementation by various institutional means. However, as such data are rarely directly available and very time-consuming to produce, it has not always been possible to test systematically the impact of these norms at the individual level, so as to be able to tell the whole story in laying bare the mechanisms whereby norms translate into specific constraints.

\section{Social construction of masculinity and fertility decline}

As the Catholic Church did not clearly articulate the prohibition of contraception until 1925-30, and as the Protestant Church also remained silent, it was, in fact, state policies that shaped the moral acceptability of contraception in particular and the norms governing sexuality and procreation more generally. Indeed, during the period of the first fertility transition, state institutions gained importance in regulating family life, compared to religious or other traditional institutions; they took over many tasks that interfered with fertility decisions (such as education, welfare and morality) and that were traditionally the churches' remit. These state institutions also became more efficient than the religious ones: they could enforce policies that constrained all families, and not only those who felt a sense of attachment to a religious community.

Recent studies emphasise the impact of the public debate on birth control. On the one hand, the existence of such a debate is supposed to speed up the generalisation of contraceptive practices by diminishing the weight of taboos relative to sexuality and, consequently, the moral costs of contraception. ${ }^{40}$ On the other hand, this public debate helped to legitimise contraceptive practices and parents with numerous children may have come to be stigmatised as irresponsible and so the social costs of having numerous children increased.

I tested the hypothesis that state policies, by tolerating or prohibiting this public debate, favoured traditional norms or permitted the establishment of new rules regarding sexual issues. As these norms and rules were always gender specific, these state policies participated in the reconstruction of the gender system, redefining the respective rights and duties of women and men in regard to sexuality and contraception and thereby their bargaining power in fertility decisions. Again, it must be assumed that such a process is influenced by the religious and political settings.

Catholic culture in Fribourg promoted a fatalist conception of family size, and parents were told to accept all the children that 'God might give them'. This fatalism weighed heavily on women, especially if we bear in mind the concept of marital debt, namely the wife's obligation not to deny sexual gratification to her husband. This ideology strengthened men's rights to marital sexuality and favoured frequent sexual intercourse, thereby sustaining high levels of fertility. This concept of Catholic morality was reinforced during the period under study. Girls' education gave the highest priority to moral behaviour, stressing obedience, innocence and purity; women were to be 
totally ignorant about sexual issues and behave as obedient wives. At the same time, the political context impeded opposition to this Catholic morality. The conservative authorities prohibited any public debate on sexual issues, in order to avoid discussion that could have weakened the credibility of the Catholic Church, their best political ally. The neo-Malthusian movement, very active in French-speaking Switzerland at the beginning of the twentieth century, was not allowed to organise any conference or publish any materials that advocated birth control. Consequently, no other opinion openly challenged traditional Catholic morality and its professed inequality between the spouses, thus maintaining a state of unequal bargaining power in fertility decisions.

In the Protestant canton by contrast, state policies tolerated public debate on birth control, through which a good example of the process of gendering sexual rights can be read. ${ }^{41}$ Contraceptive information was only considered problematic for certain categories of men such as bachelors and workers, this latter delineation being a matter of controversy according to the political ideology of the protagonists. ${ }^{42}$ By contrast, access to and use of contraceptive means was always considered unthinkable for women of all social classes. This wide consensus rallied Protestant ministers, political elites of every ideology and even feminist leaders. With the rare known exception of one neoMalthusian feminist, Margarethe Faas-Hardegger ${ }^{43}$ all women engaged in feminist or philanthropic associations either kept silent about the topic or expressed a preference for marital continence against women's use of contraceptives, which were viewed as injurious to women's sensibility and dignity. ${ }^{44}$ This denial of women's rights to sexual and contraceptive information reinforced the husband's legitimacy to act unilaterally in this domain. However, a significant feature emerged in this debate that was absent in the Catholic discourse: the husband's rights were not considered to be unlimited. He had to restrict his sexual pleasure and practise birth control, out of respect for his paternal responsibilities, the well-being of his children and their chances of rising up the social ladder, as well as the health of his wife. The debate about health authorised not only the mention of sexual issues in a 'decent and respectable' way; it also allowed so-called bourgeois feminists to express an astonishingly vehement denunciation of the 'sexual exploitation of women in marriage' ${ }^{45}$ Such public debate modified the norms of masculinity and fatherhood by challenging the unlimited masculine prerogatives in marital sexuality and in stressing men's responsibilities for the family. These changes affected the social costs of numerous children for men and thereby encouraged convergence between wives' and husbands' motivations for fertility control.

How can the impact of these changing norms on reproductive behaviour be measured? Is it possible to construct indicators that reveal such a convergence of spouses' motivation for birth control? My idea was to observe, comparing Catholic and Protestant couples, the effect of a factor generally associated with an increase in the bargaining power of women; their participation in the labour market. It can be assumed that Catholic and Protestant working mothers in the industrialised villages experienced the same working conditions, because the two factories belonged to the same company and offered similar salaries and social benefits. Therefore, they would have similar interests in birth control, since the charge of numerous children on top of paid work was a very heavy burden. But the interests of Catholic and Protestant husbands would have differed, if we assume that Protestant men integrated the changing norms of masculinity demanding sexual self-control and familial responsibilities. These husbands were already motivated to practise birth control whatever their wives' position in the labour 
market, and these women did not need to convince them. Consequently, differences in fertility between working mothers and non-working mothers should not be significant in the Protestant sample, all others variables being controlled. In the Catholic sample, by contrast, differences in motivation between spouses remained high. Therefore, only the women who had more leverage to impose their interest in fertility control should have been able to reduce their fertility, as in the case for working mothers.

To test this hypothesis, I measured, for each mother, the impact of diverse variables on the probability of another birth in a shorter time. Among the independent variables, such as mother's age, death of the previous child that terminated the contraceptive effect of lactation, or husband's occupation as indicator of the socio-economic category, I introduced the variable factory worker - indicating if the mother was or was not working in the factory. The same model was then applied separately to the Protestant and the Catholic sample, and the results confirmed my assumptions. The variable factory worker had no significant impact on fertility for Protestant mothers. In the Catholic sample, however, the same variable did have a significant effect. For Catholic mothers who worked in the factory, the risk of another birth was reduced by 16 per cent, compared to the other Catholic mothers, whatever the husband's occupation or other controlled variables.

This kind of analysis and these results may raise interpretative problems and technical criticisms that have to be debated, but they constitute an attempt to capture the impact of gender norms and bargaining power between spouses on the demographic process of fertility decline. The existence of certain norms in various kinds of discourses is not evidence of their impact on fertility behaviour.

\section{Conclusion}

Historical demographers cannot avoid incorporating gender into their explanations of historical trends of fertility, mortality, nuptiality and migration. Attention to the social process of gendering is actually a key element for capturing the linkage between individual lives and larger historical processes, and this linkage is crucial to explain the mechanisms historical demographers strive to identify. Recent developments in the discipline provide useful technical and theoretical tools to achieve this goal: the individual-oriented approach and the statistical models of event-history analysis; the application of institutional economics to study intra-family inequalities and bargaining power; the enlargement of cultural components of demographic behaviour, including gender norms; and last but not least, the analysis of institutions, especially the state. These are invaluable tools that allow economic and cultural features to be translated into an understanding of the rights and duties of individuals and thereby into the effective costs and benefits that influence individual behaviour. As these rights and duties are historically gendered, any explanation of demographic behaviour must integrate this dimension.

This study of the first fertility transition in Switzerland challenges the usual explanation of the delay of Catholic families in the adoption of birth control, attributed to the religious norms against contraception, and proposes two alternative mechanisms that make use of the concept of gender. The first one focuses on gender inequalities in access to education, much pronounced in the Catholic culture, which permitted Catholic parents to avoid major costs in educating their female children and postpone 
the necessity of birth control. The second consists in the historical change in norms of masculinity and fatherhood in Protestant culture, which was absent among Catholics, which increased the social costs of numerous families and made the motivation for fertility control between wives and husbands converge.

Certainly, this integration of gender into explanatory mechanisms requires the exploration of new fields and sources not always familiar to historical demographers. Moreover, models need to be improved by bringing together qualitative and quantitative analysis, while methodological procedures that enable the linkage of demographic behaviour with gender norms and the meanings men and women give to their experiences need to be used.

Conversely, the history of gender could benefit from the results gained in historical demography. This discipline provides empirical evidence of the changes of fundamental elements in the lives of men and women in the past - changing life expectancies; whether or not they could get married and how selection of a spouse operated; if they became parents of numerous or reduced families. Historical demography informs us of who composed the households, who worked at home and who entered the labour market, who migrated or not. All these changes modified the social positions of men and women and their respective power relations. Furthermore, many hypotheses elaborated in gender history by analysis of norms and institutions could be tested systematically on the individual level, thanks to the databases constituted by research in historical demography. Why then not use the data, the models and the statistical procedures produced in historical demography? Why not convince researchers in this field to integrate systematically some variables pertinent for gender analysis? A great challenge, but undoubtedly a fruitful enterprise.

\section{Notes}

The author wishes to thank Professor Leonore Davidoff for her encouragement and careful reading of an earlier draft of this essay. I am also grateful to the two anonymous reviewers for helpful comments and to the editors of Gender \& History who have worked to improve the English of a French-speaking scholar.

1. The connection was notably introduced by Alison Mackinnon, 'Were Women Present at the Demographic Transition? Questions from a Feminist Historian to Historical Demographers', Gender \& History 7 (1995), pp. 222-40; Peter McDonald, 'Gender Equity in Theories of Fertility Transition', Population and Development Review 26 (2000), pp. 427-39. For more recent research: Angélique Janssens (ed.), Gendering the Fertility Decline (Bern: Peter Lang, 2007). Historical demography was also influenced by demographic research on contemporary societies: Nora Federici, Karen Oppenheim Mason, Sølvi Sogner (eds), Women's Position and Demographic Change (Oxford: Clarendon Press, 1993); Stéphanie Condon, Michel Bozon and Thérèse Locoh (eds), Démographie, sexe et genre: Bilan et perspectives, collection 'Dossiers et recherches' 83 (Paris: INED, 2000); Irene Tazi-Preve, 'Gender Trouble and Fertility Decline. Gender in Demography', paper presented at the Fifth European Feminist Research Conference, 20-24 August 2003, Lund University, Sweden.

2. See, e.g., Ansley J. Coale and Susan Cotts Watkins (eds), The Decline of Fertility in Europe - The Revised Proceedings of a Conference on the Princeton European Fertility Project (Princeton: Princeton University Press, 1986); John R. Gillis, Louise A. Tilly and David Levine, The European Experience of Declining Fertility: A Quiet Revolution 1850-1970 (Cambridge MA, and Oxford: Blackwell, 1992); Susan Greenhalgh (ed.), Situating Fertility: Anthropology and Demographic Inquiry (Cambridge: Cambridge University Press, 1995).

3. Virginia Woolf, A Room of One's Own (1928; repr. London: Penguin Books, 2000), p. 47.

4. For a more documented discussion: Louise A. Tilly, 'Women's History and Family History: Fruitful Collaboration or Missed Connection?', Journal of Family History 12 (1987), pp. 303-15; Megan Doolittle, 'Close Relations? Bringing Together Gender and Family in English History', Gender \& History 11 (1999), 
pp. 542-54 and 'The Family and the Historian', in Leonore Davidoff, Megan Doolittle, Janet Fink and Katherine Holden, The Family Story - Blood, Contract and Intimacy, 1830-1960 (London and New York: Longman, 1999), pp. 16-50.

5. E.g., Gisela Bock, 'Challenging Dichotomies: Perspectives on Women's History', in Karen Offen, Ruth Roach Pierson and Jane Rendall (eds), Writing Women's History (London: Macmillan, 1991), pp. 1-23; Françoise Thébaud, Ecrire l'histoire des femmes (Fontenay/St-Cloud, ENS: 1998), pp. 66-92.

6. Maïté Albistur and Daniel Armogathe, Histoire du féminisme français (Paris: Des femmes, 1977); Sylvia Pankhurst, The Suffragette Movement (1931; repr. London: Virago, 1977); Susanna Woodtli, Du féminisme à l'égalité politique: Un siècle de luttes en Suisse, 1868-1971 (Lausanne: Payot, 1977).

7. John Gillis, 'Gender and Fertility Decline among the British Middle Classes', in Gillis, Tilly and Levine, European Experience of Declining Fertility, pp. 30-47.

8. Thébaud, Ecrire l'histoire des femmes, p. 79.

9. Allan Sharlin, 'Urban-Rural Differences in Fertility in Europe during the Demographic Transition', in Coale and Cotts Watkins (eds), Decline of Fertility in Europe, pp. 234-60.

10. Mackinnon, 'Were Women Present at the Demographic Transition?'

11. Ellen C. DuBois et al., Feminist Scholarship: Kindling in the Groves of Academe (Urbana: University of Illinois Press, 1985), p. 21.

12. Paola Tabet, 'Fertilité naturelle, reproduction forcée', in Paola Tabet, La Construction sociale de l'inégalité des sexes: Des outils et des corps (1985; repr. Paris: L'Harmattan, 1998), pp. 80-86.

13. Susan Cotts Watkins, 'If All We Knew About Women Was What We Read in Demography, What Would We Know?', Demography 30 (1993), pp. 551-77.

14. Nancy Folbre, 'Of Patriarchy Born: The Political Economy of Fertility Decisions', Feminist Studies 9 (1983), pp. 261-84.

15. George Alter, Family and the Female Life Course: The Women of Verviers, Belgium 1849-1880 (Madison: Wisconsin University Press, 1988).

16. Robert A. Pollak, 'A Transaction Cost Approach to Families and Households', Journal of Economic Literature 23 (1985), pp. 581-608.

17. Laurel Cornell et al., 'Family Strategy: A Dialogue', Historical Methods 20 (1987), pp. 113-25.

18. Carmen Sarasúa, 'Understanding Intra-Family Inequalities: The Montes de Pas, Spain, 1700-1900', History of the Family 3 (1998), pp. 173-97.

19. George Alter, 'Theories of Fertility Decline: A Nonspecialist's Guide to the Current Debate', in Gillis, Tilly and Levine (eds), The European Experience of Declining Fertility, pp. 13-27.

20. Ronny Lesthaeghe, 'La deuxième transition démographique dans les pays occidentaux: Une interprétation', in Dominique Tabutin, Thierry Eggericky and Catherine Gourbin (eds), Transitions démographiques et sociétés (Louvain-la-Neuve: Chaire Quételet, 1995), pp. 133-80.

21. Simon Szreter, Robert A. Nye and Frans van Poppel, 'Fertility and Contraception during the Demographic Transition: Qualitative and Quantitative Approaches', Journal of Interdisciplinary History 34 (2003), pp. 141-54. This special issue provides interesting case studies illustrating this connection between demography, anthropology and cultural history.

22. Kate Fisher, "She Was quite Satisfied with the Arrangements I Made": Gender and Birth Control in Britain (1920-1950)', Past and Present 169 (2000), pp. 160-93.

23. Wally Seccombe, 'Men's "Marital Rights" and Women's "Wifely Duties": Changing Conjugal Relations in the Fertility Decline', in Gillis, Tilly and Levine (eds), The European Experience of Declining Fertility, pp. 66-84; Diana Gittins, Fair Sex: Family Size and Structure, 1900-1939 (London: Hutchinson, 1982).

24. John R. Gillis, 'Gender and Fertility Decline among the British Middle Class', in Gillis, Tilly and Levine (eds), The European Experience of Declining Fertility, pp. 31-47.

25. David Kertzer, 'Political-Economic and Cultural Explanations of Demographic Behaviour', in Greenhalgh (ed.), Situating Fertility, pp. 29-52.

26. S. Ryan Johansson, "Implicit Policy" and Fertility during Development', Population and Development Review 17 (1991), pp. 377-414.

27. Simon Szreter, Fertility, Class and Gender in Britain, 1860-1940 (Cambridge: Cambridge University Press, 1996), pp. 481-8.

28. Martine Sevegrand, Les Enfants du bon Dieu: Les catholiques français et la procréation au XX $X^{e}$ siècle (Paris: Albin Michel, 1995).

29. Anne-Françoise Praz, De l'enfant utile à l'enfant précieux: Filles et garçons dans les cantons de Vaud et Fribourg, 1860-1930 (Lausanne: Antipodes, 2005), pp. 405-12.

30. John Caldwell, 'Mass Education as a Determinant of the Timing of Fertility Decline', Population and 
Development Review 6 (1980), pp. 225-55.

31. Alison Mackinnon, 'In a Class of Their Own? Swedish Women School Teachers and the Fertility Transition in the Late Nineteenth Century', Interchange 34 (2003), pp. 281-96; Daniel Scott Smith, " The Number and Quality of Children": Education and Marital Fertility in Early-Twentieth Century Iowa', Journal of Social History 50 (1996), pp. 367-92; Ann Larson, Growing up in Melbourne: Family Life in the Late Nineteenth Century (Canberra: Australian National University, 1994). See also the contributions of Alison Mackinnon, Angélique Janssens, Ida Blom, Pau Baizan and Enriqueta Camps in Janssens (ed.), Were Women Present at the Demographic Transition?

32. Archives cantonales vaudoises; Département de l'instruction publique et des cultes; Archives de l'Etat de Fribourg; Département de 1'instruction publique.

33. For further development and references on the construction of these data files, see Praz, De l'enfant utile à l'enfant précieux, pp. 559-74.

34. For the administrative sources, we explored annual reports of the cantonal governments, messages presenting the school laws, correspondence between cantonal and local administrations; our content analysis systematically compiled the terms and phrases supporting the arguments in favour of the necessity of education and regular school attendance. For the educational periodicals, we selected all articles containing the topic 'gender' in the Bulletin pédagogique, published in Fribourg since 1872, and in two corresponding periodicals for the canton of Vaud, that merged during the period: L'Ecole, published in Lausanne between 1873 and 1901, and L'Educateur, an educational periodical distributed in French-speaking Protestant Switzerland and published from 1866. The content analysis of school manuals concentrated on two reading books, one published in Fribourg, the other in Vaud, and used for children of the age eight to twelve from around 1900 until the end of the 1920s: Emile Bonjour and Louis Dupraz, Livre de lecture à l'usage des écoles primaires du canton de Vaud (Lausanne: Hoirs d'Adrien Borgeaud, 1903); Livre de lecture à l'usage des écoles primaires du canton de Fribourg (Fribourg: Fragnière, 1890). For further development of both the discourse analysis and the statistical results, see Anne-Françoise Praz, 'Ideologies, Gender and School Policy: A Comparative Study of Two Swiss Regions', Paedagogica Historica: International Journal of the History of Education 42 (2006), pp. 345-61.

35. 'Y aurait-il différence d'essence et de destinée entre l'intelligence de l'homme et celle de la femme? Toutes les deux ne seraient-elles pas appelées également à prendre pleine possession du royaume de la vérité, à glorifier Dieu par le libre et complet épanouissement de toutes leurs forces vives?', L'Ecole 25 (1883), p. 308.

36. L'Ecole (1 December 1879), p. 363.

37. 'La mère institutrice', in Bonjour and Dupraz, Livre de lecture à l'usage des écoles primaires du canton de Vaud, p. 110.

38. In the Bulletin pédagogique, the learned woman is negatively presented as: 'une nullité', 'un demi-savant', 'un demi-messieur', 'un amas de sciences qui empêche les connaissances utiles et sérieuses', 'une demoiselle à diplômes qui dédaigne le mariage et la famille'.

39. A first data file includes the 2,353 children whose school career has been reconstituted; a dummy variable is set to one if the child has attended a post-primary school. Using a logistic regression, the model measures the impact of five independent variables (sex, religion, father's occupation, birth order, death of one parent before age thirteen) on a child's chance of attending a post-primary school. A second database is constituted by time sequences of children's school career between the age of thirteen (where the respective school systems permitted the first school leaves) and eighteen (as very few children pursued their studies beyond this point). Using a Cox regression, the second model measures the risk of leaving school early according to the same variables.

40. This hypothesis is advanced by Szreter, Fertility, Class and Gender, pp. 410-11 and by John Caldwell, 'The Delayed Western Fertility Decline: An Examination of English-Speaking Countries', Population and Development Review 25 (1999), pp. 479-513.

41. For a detailed analysis of these discourses, see Anne-Françoise Praz, 'Gender, Religion and the Pace of Fertility Decline in French-Speaking Switzerland (1860-1930)', in Janssens (ed.), Were Women Present at the Demographic Transition?

42. Catherine Fussinger and Chantal Ostorero, 'La Question sexuelle-Des seuils de tolérance en reélaboration', Equinoxe 20 (October 1998), pp. 101-14.

43. Margarethe Faas-Hardegger (1882-1963), the editor of a trade union journal for women and the first Women Secretary engaged by the Swiss Federation of Trade Unions, suggested information meetings about contraception for working women, but she was met with absolute refusal by the direction of the Federation. See Ina Boesch, Gegenleben: Die Sozialistin Margarethe Hardegger und ihre politischen Bühnen (Zurich: Chronos Verlag, 2004). 
44. Anne-Marie Käppeli, Sublime Croisade: Ethique et politique du féminisme protestant, 1875-1928 (Geneva: Zoé, 1990); Ursula Gaillard and Annick Mahaim, Retards de règles: Attitudes devant le contrôle des naissances et l'avortement en Suisse du début du siècle aux années vingt (Lausanne: Ed. d'en bas, 1983).

45. In exploring the influence of the feminist movements on the British fertility decline, Szreter, Fertility, Class and Gender, p. 573, makes a similar observation: the more important impact could have been the strongly evangelical strain within feminism, which emphasised the importance of sexual continence for husbands and put into question male sexual expectations in general. 